\title{
Identification of aec $A$ mutations in Bacillus subtilis as nucleotide substitutions in the untranslated leader region of the aspartokinase II
} operon

\author{
Yang Lu, Nai-Yong Chen† and Henry Paulus* \\ Department of Metabolic Regulation, Boston Biomedical Research Institute, Boston, Massachusetts 02114, \\ and Department of Biological Chemistry and Molecular Pharmacology, Harvard Medical School, Boston, \\ Massachusetts 02115, USA
}

(Received 25 October 1990; revised 14 December 1990; accepted 4 January 1991)

\begin{abstract}
Recent genetic mapping of the aspartokinase II (lysC) operon of Bacillus subtilis [M. Petricek. L. Rutberg \& L. Hederstedt (1989) FEMS Microbiology Letters 61, 85-88; N. Y. Chen. J. J. Zhang \& H. Paulus (1989) Journal of General Microbiology 135, 2931-2940] has shown its chromosomal location to be close to the aec $A$ locus, the mutation of which leads to highly increased levels of aspartokinase II. In order to examine the relationship between $l_{y s} C$ and $a e c A$, we have cloned the control regions of the $l_{y s} C$ operon from several independent aec $A$ mutants and determined their nucleotide sequences. The nucleotide sequences of the aec $A$ mutants differed from the wild-type sequence by the substitution of one or two nucleotides at two widely separated sites in the transcribed leader region of the $l y s C$ operon. To confirm that the observed nucleotide changes are indeed responsible for the AecA phenotype and not simply the reflection of sequence polymorphisms in different $B$. subtilis strains, we introduced the same nucleotide substitutions as those observed in the aec $A$ strains into the leader region of the wild-type lys $C$ operon by oligonucleotide-directed mutagenesis. The expression of the mutagenized genes was analysed after transcriptional or translational fusion to $\operatorname{lac} Z$ in a single-copy integration vector. The levels of $\beta$-galactosidase were greatly elevated by the nucleotide substitutions, with similar increases observed in transcriptional and translational fusions. The high level of expression of $\beta$-galactosidase in the $l y s C^{\prime}-l a c^{\prime} Z$ strains with nucleotide substitutions corresponding to the aec $A$ mutations was resistant to repression by L-lysine but was completely abolished by the inactivation of the $l y s C$ promoter. These results suggest that the sites identified by nucleotide sequencing of the aec $A$ mutants are important regulatory sites in the lys $C$ operon, which exert their effect at the level of transcription involving the normal $l y s C$ promoter.
\end{abstract}

\section{Introduction}

The enzyme aspartokinase (ATP:L-aspartate 4-phosphotransferase, EC 2.7 .2 .4 ) catalyses the first step in the aspartate pathway, a complex biosynthetic pathway that leads to the biosynthesis of lysine, methionine and

* Correspondence should be sent to the Boston Biomedical Research Institute.

$\dagger$ Present address: Institute of Microbiology, Academia Sinica, Beijing, China.

Abbreviation: AEC, $S$-(2-aminoethyl)cysteine.

The nucleotide sequence data reported in this paper have been submitted to GenBank and have been assigned the accession number J03294. threonine. Bacillus subtilis has three aspartokinase isoenzymes, one of which, aspartokinase II, is controlled by lysine through repression and feedback inhibition (Moir \& Paulus, 1977; Zhang et al., 1990). The growth of $B$. subtilis is inhibited by the lysine analogue $S$-(2aminoethyl)cysteine (AEC), and mutants resistant to AEC can readily be isolated (Vold $e t$ al., 1975). One class of AEC-resistant mutants, designated aecA, has about 50-fold elevated levels of aspartokinase II (Vold et al., 1975; Yeh \& Steinberg, 1978). Other aec A mutants have been isolated and classified by genetic mapping, but their aspartokinase II levels have not been examined (Mattioli et al., 1979; Magnusson et al., 1983). Originally, aec $A$ was thought to be a trans-acting regulatory gene (e.g. Piggot \& Hoch, 1985), but genetic mapping of the aspartokinase II operon (lysC, formerly ask) suggests 
Table 1. B. subtilis strains and plasmids

\begin{tabular}{|c|c|c|}
\hline $\begin{array}{l}\text { Sirain or } \\
\text { plasmid }\end{array}$ & Genotype or description & $\begin{array}{l}\text { Source or } \\
\text { reference }\end{array}$ \\
\hline GSY225 & pheAl trpC2 & Yeh \& Steinberg (1978) \\
\hline GSY $225-40$ & pheAl trpC 2 amyE : :lys $C^{\prime}-l a c^{\prime} Z$ (translational fusion) & This study \\
\hline GSY225-41 & Same as GSY225-40, except G to A change at $320^{*}$ of $l y s C \dagger$ & This study \\
\hline GSY225-42 & Same as GSY225-40, except $C$ to $T$ change at $476^{*}$ of lysC & This study \\
\hline GSY225-47 & Same as GSY225-41, except $\triangle \mathrm{A} 270^{*}$ in lysC $t$ & This study \\
\hline GSY $225-60$ & phe $A 1 \operatorname{trp} C 2$ amyE $:: l y s C^{\prime}-l a c^{\prime} Z$ (transcriptional fusion) & This study \\
\hline GSY225-61 & Same as GSY225-60, except $\mathrm{G}$ to A change at $320^{*}$ of $l y s C^{\dagger}$ & This study \\
\hline GSY225-62 & Same as GSY225-60, except C to T change at $476^{*}$ of lysC $\dagger$ & This study \\
\hline BGSC 1 A8 & aroDI20 lys-1 trpC2 & Dedonder et al. (1977) \\
\hline $\begin{array}{l}1 \mathrm{~A} 8-40 \\
1 \mathrm{~A} 8-41 \\
1 \mathrm{~A} 8-60 \\
1 \mathrm{~A} 8-61\end{array}$ & $\begin{array}{l}\text { aroD120 lys-1 trpC2 amy::lys } C^{\prime}-l a c^{\prime} Z \text { (translational fusion) } \\
\text { Same as } 1 \mathrm{~A} 8-40 \text {, except } \mathrm{G} \text { to } \mathrm{A} \text { change at } 320^{*} \text { of lys } C^{\dagger} \\
\text { aroD120 lys-1 trpC2 amy }:: l y s C^{\prime}-l a c^{\prime} Z \text { (transcriptional fusion) } \\
\text { Same as } 1 \mathrm{~A} 8-60 \text {, except } \mathrm{G} \text { to A change at } 320^{*} \text { of lys } C^{\dagger}\end{array}$ & $\begin{array}{l}\text { This study } \\
\text { This study } \\
\text { This study } \\
\text { This study }\end{array}$ \\
\hline $\begin{array}{l}\text { VB217 } \\
\text { FB59 (BGSC 1A432) } \\
\text { KA120 }\end{array}$ & $\begin{array}{l}\text { pheAl trpC2 sulR aecA3 } \\
\text { aecA4 } \\
\text { pheAl trpC2 aecA5 }\end{array}$ & $\begin{array}{l}\text { Yeh \& Steinberg (1978) } \\
\text { Mattioli et al. (1979) } \\
\text { Magnusson et al. (1983) }\end{array}$ \\
\hline pJH101-AskNB & pJH101 with lys $C \dagger(1350-1645)^{*}$ insert & Zhang et al. (1990) \\
\hline M13-40 & M13mp19 carrying lysC $\dagger(212-654)^{*}$ in SmaI site & Chen \& Paulus (1988) \\
\hline M13-41 & Same as M13-40, except $G$ to $A$ change at $320^{*}$ & This study \\
\hline M13-42 & Same as M13-40, except $C$ to $T$ change at $476^{*}$ & This study \\
\hline M13-47 & Same as $\mathrm{M} 13-41$, except $\triangle \mathrm{A} 270^{*}$ & This study \\
\hline pIS112 & lacZ amp cat & Lewandoski \& Smith (1988) \\
\hline pIS $112-40$ & $\begin{array}{l}\text { pIS } 112 \text { with lys } C \dagger(212-654)^{*} \text { from M13-40 } \\
\text { inserted between the EcoRI and BamHI sites }\end{array}$ & This study \\
\hline pIS112-41 & Same as pIS112-40, except $G$ to $A$ change at $320^{*}$ & This study \\
\hline pIS112-42 & Same as pIS112-40, except $C$ to T change at $476^{*}$ & This study \\
\hline pIS112-47 & Same as pIS112-41, except $\triangle \mathrm{A} 270^{*}$ & This study \\
\hline $\mathrm{pDH} 32$ & spoVG-lacZ amp cat amyE(front) amyE(back) & D. J. Henner \\
\hline pDH $32-40$ & $\begin{array}{l}\text { pDH32 with a EcoRI-ClaI fragment containing the } \\
\text { translational lys } C^{\prime}-l a c^{\prime} Z \text { fusion from pISI } 12-40 \text { in } \\
\text { place of the original EcoRI-ClaI segment }\end{array}$ & This study \\
\hline pDH32-41 & Same as pDH32-40, except $G$ to A change at $320^{*}$ & This study \\
\hline pDH32-42 & Same as pDH32-40, except $C$ to $T$ change at $476^{*}$ & This study \\
\hline $\mathrm{pDH} 32-47$ & Same as pDH32-41, except $\triangle \mathrm{A} 270^{*}$ & This study \\
\hline pDH $32-60$ & $\begin{array}{l}\text { pDH32 with lysC } \dagger(212-654)^{*} \text { from M13-40 } \\
\text { inserted between the EcoRI and BamHI sites }\end{array}$ & This study \\
\hline $\mathrm{pDH} 32-61$ & Same as pDH32-60, except $G$ to $A$ change at $320^{*}$ & This study \\
\hline pDH32-62 & Same as pDH32-60, except $C$ to $T$ change at $476^{*}$ & This study \\
\hline
\end{tabular}

* Nucleotide residues are numbered according to the system of Chen et al. (1987) (see Fig. 3).

† Formerly referred to as the ask gene (Zhang et al., 1989) but now renamed lysC to conform with the designation of the gene for the lysine-sensitive aspartokinase of $E$. coli.

that $\operatorname{aec} A$ is located in the $5^{\prime}$-untranslated region of the aspartokinase II transcription unit (Petricek et al., 1989; Chen et al., 1989).

The recent cloning and sequencing of the entire aspartokinase II operon and adjacent regions of the $B$. subtilis chromosome (Chen et al., 1987, 1989) allowed us to address the question whether aec $A$ mutations are due to changes in the nucleotide sequence of lysC or its control region. In this paper, we describe the cloning and nucleotide sequence analysis of the upstream portion of the $l y s C$ operon from three independent aec $A$ mutants, originally isolated by Yeh \& Steinberg (1978), Mattioli et al. (1979) and Magnusson et al. (1983) respectively. The nucleotide sequence of the transcribed $l y s C$ leader region of the aec $A$ mutants was found to differ from that of the aec $\mathrm{A}^{+}$parent strain by the replacement of one or two nucleotides at two widely separated sites. The same nucleotide substitutions were then introduced into the leader region of the wild-type lysC operon by oligonucleotide-directed mutagenesis to determine whether these nucleotide changes are indeed responsible for the AecA phenotype and define potential cis-acting regulatory sites in the lys $C$ operon.

\section{Methods}

Bacterial strains and growth conditions. The strains of Bacillus subtilis and the plasmids used in this work are listed in Table 1. LB was used as 
a rich medium; the minimal medium was that of Anagnostopoulos \& Spizizen (1961), supplemented with $\mathrm{FeSO}_{4}\left(10 \mathrm{mg} \mathrm{l}^{-1}\right) \quad \mathrm{CaCl}_{2}$ (20 $\left.\mathrm{mg} \mathrm{l}^{-1}\right)$, and glucose $\left(5 \mathrm{~g} \mathrm{l}^{-1}\right)$, and with amino acids and antibiotics when appropriate. The effect of lysine limitation or lysine excess was studied using strains derived from the lysine auxotroph $B$. subtilis $1 \mathrm{~A} 8$ in minimal medium supplemented with $0.016 \mathrm{mM}$ - or $5 \mathrm{mM}$ L-lysine, respectively; other supplements were $0.3 \mathrm{~mm}$ each of Lphenylalanine, $\mathrm{L}$-tyrosine and L-tryptophan, and $5 \mu \mathrm{g}$ chloramphenicol $\mathrm{ml}^{-1}$. The minimal medium was inoculated with 0.025 vol. of starter culture in the rich medium of Stansly et al. (1947) and the cells were harvested $1 \mathrm{~h}$ after growth had stopped due to lysine limitation in the lysine-deficient medium or at the corresponding density (70-80 Klett units with filter no. 54) in the lysine-rich medium. Plasmids were propagated and maintained in Escherichia coli $\mathrm{DH} 5$ [deoR recAI end AI hsdR17 $\left(r_{\mathrm{k}}^{-} m_{\mathrm{k}}^{+}\right)$supE44 $\lambda^{-}$gyrA96] or E. coli $\mathrm{HB} 10 \mathrm{~L}$ [ $\Delta(\mathrm{gpt}$-proA $) 62$ leuB6 thi-1 lac YI hsd $S_{B} 20$ recA rpsL20(Str') ara-14 galK2 xyl-5 mtl-1 mcrB $B_{B}$ supE44].

Isolation and sequence analysis of the lys C operon from aec A strains. The upstream portions of the $l y s C$ operon of the aec $A$ strains VB217, FB59 and KA1 20 were isolated from the $l y s C:$ :cat derivatives of these strains, obtained by the method of Ferrari et al. (1983) through integration of plasmid pJH101-AskNB as described by Zhang et al. (1990). Briefly, DNA was isolated from the lys $C::$ cat strains, digested with either Pst I or EcoRI and self-ligated at low DNA concentrations The ligation mixtures were used to transform Escherichia coli $\mathrm{HB} 101$ or DH5, and chloramphenicol-resistant colonies were selected for plasmid isolation. The plasmids thus obtained were subjected to restriction analysis to ascertain the presence of DNA surrounding the lys $C$ locus. A positive plasmid isolate derived from each of the aec $A$ strains was selected for nucleotide sequence determination by the dideoxynucleotide method (Sanger et al., 1977) using modified T7 DNA polymerase (Tabor \& Richardson, 1987). DNA sequencing was done either after transfer of a $1.6 \mathrm{~kb}$ Pst I-BamHI fragment of the cloned genes to M13mp18 or M13mp19 (for B. subtilis VB217), or directly on the double-stranded plasmids (for $B$. subtilis FB59 and KA120), using appropriate synthetic sequencing primers. The nucleotide sequence was determined for both strands of the $l y s C$ promoter and leader regions. Additional sequences, which ranged from residues 1 to 1360 for strain VB217, and from residues 235 to 714 for strains FB59 and $\mathrm{KA} 120$, were obtained by the analysis of only one strand.

Nucleotide residues in $l y s C$ and adjacent regions are referred to by the numbering system of Chen et al. (1987).

Oligonucleotide-directed mutagenesis. Site-directed mutagenesis was carried out by the phosphorothioate method of Nakamaye \& Eckstein (1986), employing a commercial reagent kit (Amersham), or by the method of Kunkel (1985). Mutagenesis employed the following deoxyribo-oligonucleotides, which were synthesized by the phosphoramidite method using the BioSearch Cyclone DNA synthesizer (the residues that differ from the wild-type sequence are underlined): oligonucleotide 1, TATGGTGAAGATAGAGATGC (residues 304323); oligonucleotide 2, GAGGGTTATCTCGTTGTTCA (residues 471-490); oligonucleotide 3, GATAGAGATGCGAACTTC (residues 313-330). Mutagenesis was carried out on a derivative of bacteriophage M13mp19 (phage M13-40), constructed, as described by Chen \& Paulus (1988), by ligating a blunt-ended DdeI fragment, corresponding to residues 212-654, into the SmaI site of the M13mpl9 polylinker (Fig 1). The nucleotide sequence of the mutagenized $\mathrm{M} 13 \mathrm{mp} 19$ derivatives was confirmed by direct sequence determination as described by Zhang et al. (1990). The following mutant bacteriophages were obtained, with the mutagenic oligonucleotide used and the sequence differences from the parental phage M13-40 indicated in parentheses: M13-41 (oligonucleotide 1; $\mathrm{G}^{320} \rightarrow \mathrm{A}^{320}$ ), M13-42 (oligonucleotide 2; $C^{476} \rightarrow T^{476}$ ), and M13-47 (oligonucleotide $3 ; G^{320} \rightarrow A^{320}$ and $\Delta A^{270}$ ).
The double mutant M13-47 was obtained serendipitously, perhaps on account of partial complementarity of oligonucleotide 3 with residues 266-280.

Construction of single-copy lac $Z$ fusion vectors. The lys $C$ leader region from M13-40 or from its mutagenized derivatives was excised from the polycloning sites by cleavage with $E c o \mathrm{RI}$ and $B a m \mathrm{HI}$ and used in the construction of either transcriptional or translational $l a c Z$ fusions (Fig. 1). For transcriptional fusions, the EcoRI-BamHI fragment carrying the $l_{y s} C$ leader together with the first 15 codons of aspartokinase II was ligated to the corresponding sites of the single-copy integration vector pDH32, which is similar to ptrpBGI (Shimotsu \& Henner, 1986) except that it carries a $s p o V G^{\prime}-l a c^{\prime} Z$ fusion instead of $\operatorname{trp} E^{\prime}-l a c^{\prime} Z$ (D. Henner, personal communication). The nucleotide sequence at the fusion junction is shown in Fig. 2. Plasmid pDH32 and its derivatives can replicate in $E$. coli but not in $B$. subtilis, where it integrates into the chromosomal amyE locus through the $3^{\prime}$ and $5^{\prime}$ segments of $a m y E$ which flank the lac $Z$ fusion protein and the cat gene of pDH32 (Shimotsu \& Henner, 1986). Accordingly, the desired $l y s C^{\prime}-l a c^{\prime} Z$ transcriptional fusion plasmid pDH32-60 and its mutagenized derivatives were isolated by transforming E. coli DH5, selecting for chloramphenicolresistant transformants, and screening of the plasmids obtained from selected transformants by restriction analysis to confirm that they were the desired recombinants. After linearization by cleavage at the unique PstI site, pDH32-60 and its derivatives were used to transform $B$. subtilis GSY225 or $1 \mathrm{~A} 8$. amyE: :lys $C^{\prime}-l a c^{\prime} Z$ derivatives of $B$. subtilis GSY 225 or $1 \mathrm{~A} 8$ were isolated as chloramphenicol-resistant colonies and were screened for the absence of amylase activity to ascertain that integration had indeed occurred at the amylase locus.

Translational $l y s C^{\prime}-l a c^{\prime} Z$ fusion plasmids were constructed along similar lines, except that the EcoRI-BamHI fragment from M13-40 or its derivatives was first inserted into the corresponding sites of pISI 12 (Lewandoski \& Smith, 1988) in order to achieve the in-phase fusion of codon 15 of aspartokinase II with the codons for the amino-terminal sequence of $\beta$-galactosidase (Fig. 1). The sequence of the fusion junction is shown below, with the residues derived from $l y s C$ in italics:

$$
\text { Gly Ser Gly Asp Pro Val Val Leu }
$$$$
\text { GGC TCA GGG GAT CCC GTC GTT TTA }
$$

The resulting $l y s C^{\prime}-l a c^{\prime} Z$ fusion plasmid (pIS112-40 and derivatives) was used to transform $E$. coli DH5, with selection for ampicillin resistance. The DNA segment encoding the lys $C$ leader region and the amino-terminal portion of the aspartokinase II- $\beta$-galactosidase fusion protein was excised from pIS112-40 with EcoRI and $C l a I$ and used to replace the $E c o$ RI-ClaI segment of the single-copy integration vector $\mathrm{pDH} 32$. The desired translational $l y s C^{\prime}-l a c^{\prime} Z$ fusion plasmid $\mathrm{pDH} 32-$ 40 and its mutagenized derivatives were isolated and integrated into the $a m y E$ locus of $B$. subtilis GSY225 or 1 A8 to yield $a m y E:$ : lys $C^{\prime}-l a c^{\prime} Z$ derivatives in a manner similar to that described above for the corresponding transcriptional fusions.

Enzyme assays. For measurements of aspartokinase, cells were disrupted by passage through a French pressure cell. The lysate was centrifuged at $100000 \mathrm{~g}$ for $1 \mathrm{~h}$ and the supernatant solution was assayed for aspartokinase II by measuring the lysine-sensitive and aspartate-dependent formation of acyl phosphate from $\left(\gamma^{32}\right.$ P]ATP as described previously (Paulus \& Gray, 1967). For the measurement of $\beta$ galactosidase, cultures of $B$. subtilis were harvested in mid-exponential phase ( 70 Klett units with no. 54 filter), washed and suspended in $0.1 \mathrm{M}$ -

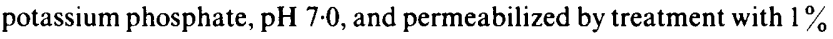
(v/v) toluene at $25^{\circ} \mathrm{C}$ for $10 \mathrm{~min}$. $\beta$-Galactosidase was then assayed essentially as described by Miller (1972), except that incubations were carried out at $37^{\circ} \mathrm{C}$. Protein concentration was determined by the method of Bradford (1976). 


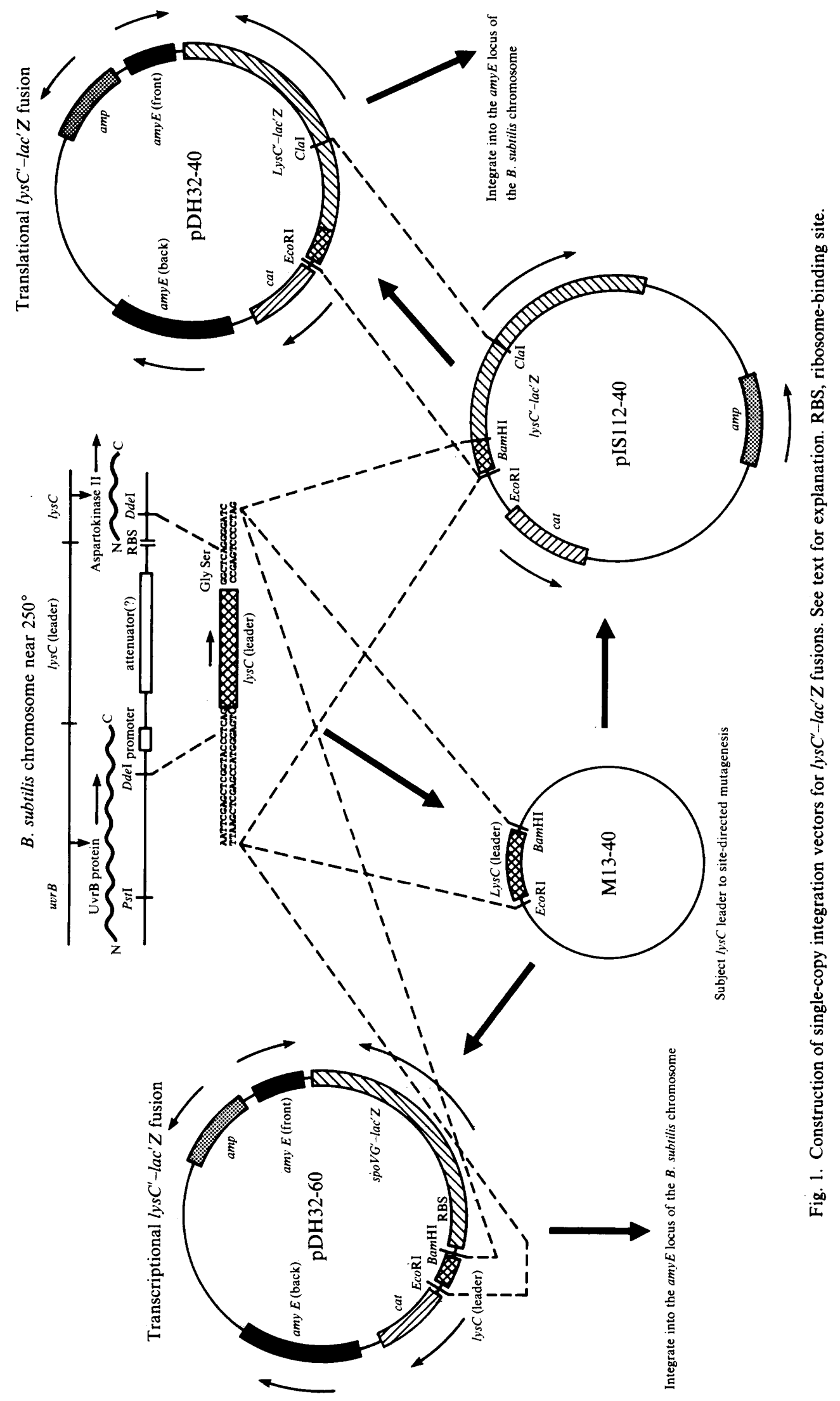


lysC

Gly Ser Gly Asp Pro Gln Leu Glu Leu Ile His. GGC TCA GGG GAT CCC CAG CTT GAA TTG ATA CAC TAA

\section{SPOVG RBS \\ TgCtTtTataTAGgGaAaAgGtgGtgaActact}

spovG $-1 a c^{\prime} Z$

Fmet Glu Val Thr Asp Val Arg Leu Arg Val Asp Arg Glu GTG GAA GTT ACT GAC GTA AGA TTA CGG GTC GAC CGG GAA

Fig. 2. Nucleotide sequence of the fusion junction of the $s p o V G^{\prime}-l a c^{\prime} Z$ fusion. The residues derived from $l y s C$ are shown in italics. RBS, ribosome-binding site.

\section{Results and Discussion}

\section{Effect of aecA mutations on aspartokinase levels}

Two classes of mutants of B. subtilis resistant to the lysine analogue $A E C$ have been characterized, which differ in the levels of aspartokinase II (Vold et al., 1975) and in the overproduction of lysine (Mattioli et al., 1979). Mutants of the $a e c B$ class have normal levels of aspartokinase II, do not overproduce lysine, and map near the threonine operon at $280^{\circ}$. In contrast, the aec $A$ mutants, which are the subject of this paper, have elevated levels of aspartokinase II, overproduce lysine, and map near the aspartokinase II operon (lysC) at $250^{\circ}$. However, of three aec $A$ mutants that have been described in the literature, only one has actually been shown to produce derepressed levels of aspartokinase II (Yeh \& Steinberg, 1978), whereas the others (Mattioli et al., 1979; Magnusson et al., 1983) were classified as aec $A$ primarily on the basis of genetic mapping. It was therefore of interest to compare the aspartokinase II levels of these aecA strains to determine whether they indeed represent a biochemically homogeneous group.

The levels of aspartokinase II in extracts of three independently isolated aecA mutants, B. subtilis strains VB217 (Yeh \& Steinberg, 1978), FB59 (Mattioli et al., 1979) and KA120 (Magnusson et al., 1983), were examined and found to be between 33 and 66 times higher than in extracts of the wild-type $\left(\operatorname{aec} A^{+}\right)$strain during exponential growth in rich medium, where aspartokinase II is ordinarily repressed (Table 2). On the other hand, the sensitivity of aspartokinase II to feedback inhibition by L-lysine is not significantly altered in aecA strains, the values reported in Table 2 being lysine-sensitive aspartokinase activities. Indeed, the derepressed aec $A$ strain VB217 served as the original source for the purification of lysine-sensitive aspartokinase II (Moir \& Paulus, 1977). It is of interest that, in spite
Table 2. Aspartokinase II activity in aec A mutants of B. subtilis

\begin{tabular}{lcc}
\hline \hline Strain & aec A allele & $\begin{array}{c}\text { Aspartokinase II activity* } \\
\left(\mathrm{nmol} \mathrm{min}^{-1} \mathrm{mg}^{-1}\right)\end{array}$ \\
\hline GSY225 & aec $A^{+}$ & $<9$ \\
VB217 & aec 3 & 630 \\
FB59 & aec 44 & 290 \\
KA120 & aec 55 & 470 \\
\hline \hline
\end{tabular}

* Aspartokinase II activity was measured as lysine-sensitive aspartokinase activity in extracts of cells harvested in the mid-exponential phase of growth in LB medium as described in Methods.

of the diverse origins of the three aec $A$ strains, their aspartokinase II levels differ not more than twofold. We can therefore conclude that derepressed levels of aspartokinase II are a common feature of $\operatorname{aec} \boldsymbol{A}$ mutants and that the extent of derepression in the mutants studied varies over a relatively narrow range.

\section{Nucleotide sequence of the lysC leader region of aec $A$ mutants}

The promoter-proximal portion of the lys $C$ operon of the three aecA strains was cloned by the method of Ferrari et al. (1983) after inactivation of the aspartokinase II gene by recombination with a $\mathrm{pJH} 101$ derivative carrying a segment of the aspartokinase II coding region. The upstream portion of the $l y s C$ gene and adjoining regions was then recovered from chromosomal EcoRI or Pst I libraries of the aspartokinase II-negative strains (lys $C:$ :cat) after self-ligation and screening for plasmids that conferred chloramphenicol-resistance upon transformation of $E$. coli. The same procedure had been applied earlier to the lys $C$ operon of $B$. subtilis ATCC 6051 and GSY225, and subsequent sequence determination showed no differences between the $l y s C$ operons of these strains and of $B$. subtilis 168 , from which the lys $C$ operon was originally isolated (Zhang et al., 1990). [A sequence difference was found in the coding region for the UvrB protein just upstream of the $l y s C$ operon, with strains ATCC 6051 and GSY225 differing from strain 168 by the insertion of $C$ at residue 201 and a deletion of $G$ at residue 210 , with a resulting short frame-shift in the $u v r B$ coding sequence and substitution of Ala-Ala-Ala for Gln-Arg-Arg at residues 578-580 of the UvrB protein (N. Y. Chen \& H. Paulus, unpublished results). This substitution occurs in a relatively unconserved region of the UvrB protein (Chen et al., 1989) and may be an instance of sequence polymorphism between different strains of $B$. subtilis that has no functional significance.] On the other hand, the nucleotide sequences of the lys $C$ leader region from the aec $A$ mutants differed from that of 


\section{Strain of B. subtilis \\ $168\left(\operatorname{aec} A^{+}\right)$ $\mathrm{VB} 217$ (aec $A)$ \\ FB59 (aec A)}

$\mathrm{KA} 120(\operatorname{aec} A)$

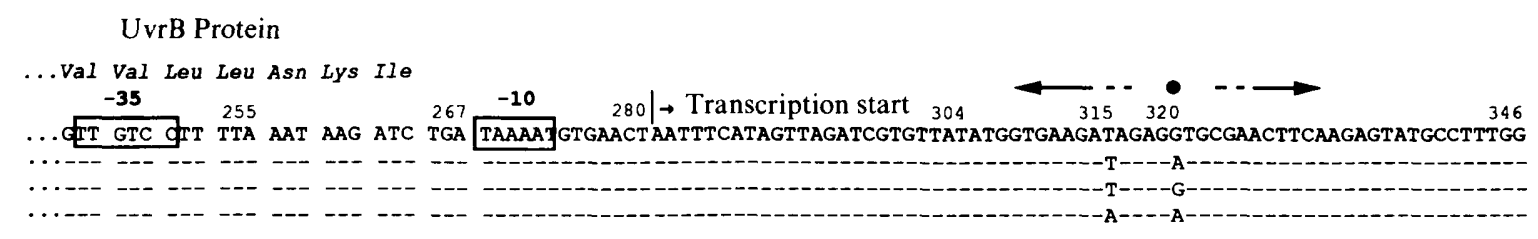

\section{$168\left(\operatorname{aec} A^{+}\right)$}

VB217 (aec $A)$

FB59 (aec $A)$

$\mathrm{KAl} 20(\operatorname{aec} A)$

Putative attenuator leader peptide

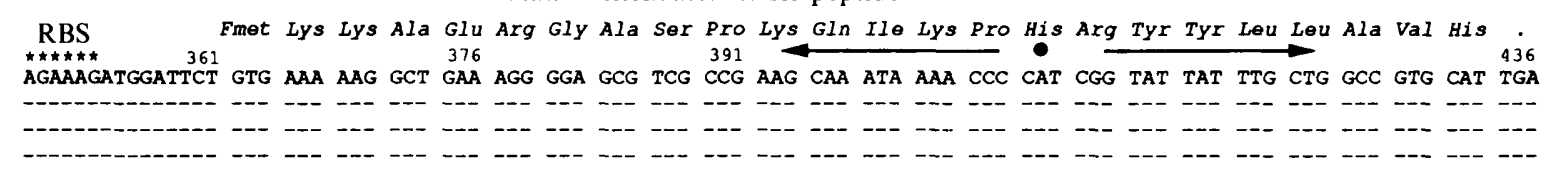

$168\left(\mathrm{aec}^{+}\right)$
$\mathrm{VB} 217(\mathrm{aec} A)$

VB217 (aec $A)$

FB59 (aecA)

KA120 (aec $A)$
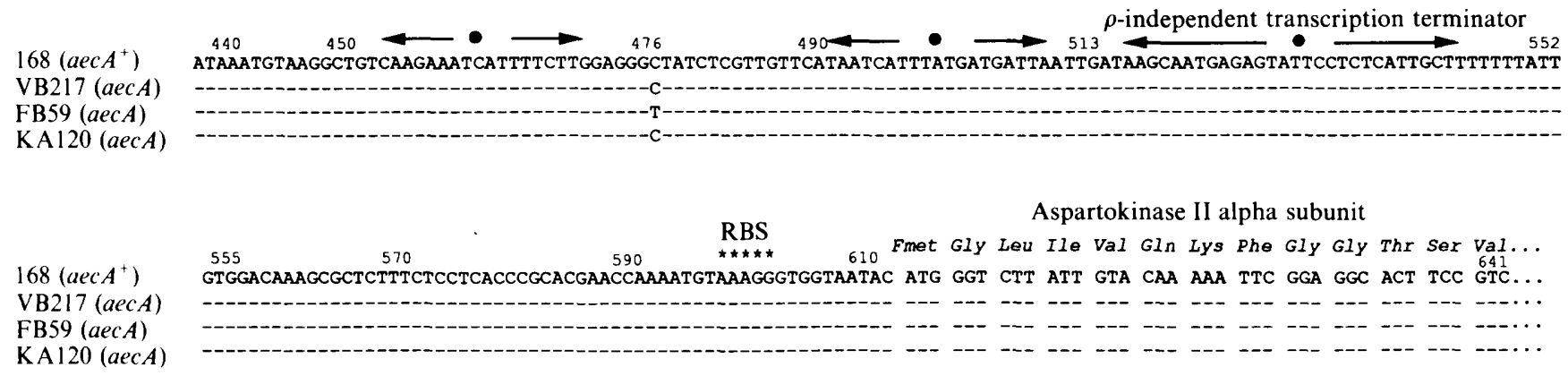

Fig. 3. Nucleotide sequence of the $l y s C$ leader region from $B$. subtilis 168 and from the aec $A$ strains VB217, FB59 and KA120. The $l y s C$ sequences of strain 168 is shown in its entirety, but the $l y s C$ sequences of the aec $A$ mutants are shown only where they differ from strain 168. The sequence is annotated to show reading frames and elements of potential regulatory significance (Chen et al., 1987). The arrows indicate regions with dyad symmetry. RBS, ribosome-binding site.

the aec $\mathrm{A}^{+}$strains by one or two nucleotide substitutions: a $\mathrm{G}$ to A change at position 320 in strain VB217 (aecA3), a $\mathrm{C}$ to $\mathrm{T}$ change at position 476 in strain FB59 (aecA4). and a $T$ to $A$ change at position 315 as well as a $G$ to $A$ change at position 320 in strain KA120 (aecA5). These nucleotide substitutions do not affect any of the known or potential control elements identified earlier in lys $C$ (Chen et al., 1987), which include the sigma-43 promoter region, the transcription start site, the putative transcription attenuator, and the translation start site (Fig. 3). Their function in the control of $l y s C$ expression is thus not immediately obvious and it was important to determine whether the observed nucleotide changes are indeed responsible for the AecA phenotype or are merely the reflection of DNA sequence polymorphism in different strains of $B$. subtilis.

Effect of nucleotide substitutions in the lysC leader region on the expression of lys $C^{\prime}-l a c^{\prime} Z$ fusions

The question whether the nucleotide replacements observed in the aecA mutants are responsible for enhanced gene expression can be answered most directly by introducing the corresponding nucleotide changes into the wild-type lys $C$ leader region and examining the resulting phenotype. Accordingly, we used oligonucleo- tide-directed mutagenesis to effect nucleotide changes corresponding to those observed in aecA strains VB217 ( $\mathrm{G}$ to A change at residue 320 ) and FB59 ( $\mathrm{C}$ to $\mathrm{T}$ change at residue 476). In addition, we combined the nucleotide change characteristic of strain VB217 (G to $A$ at residue 320 ) with a deletion in the -10 consensus region of the lys $C$ promoter ( $\triangle \mathrm{A}$ at residue 270 ), which leads to inactivation of the promoter. The effect of these mutations on gene expression was studied in a lys $C^{\prime}-$ $\operatorname{lac}^{\prime} Z$ fusion to allow the measurement of $\beta$-galactosidase as a convenient indicator enzyme. In order to avoid possible complications due to gene dosage effects and variation in plasmid copy number, we made use of a single-copy integration vector which allowed insertion of the $l y s C^{\prime}-l a c^{\prime} Z$ fusion into the $a m y E$ locus of $B$. subtilis (Shimotsu \& Henner. 1986).

Our results show that nucleotide substitutions at residues 320 or 476 in the lys $C$ leader, corresponding to the ones found in the aecA strains VB217 and FB59, respectively, led to greatly increased levels of $\beta$ galactosidase expression, both in translational and transcriptional lys $C^{\prime}-l a c^{\prime} Z$ fusions (Table 3). The G to A substitution at residue 320 caused a 100- to 200 -fold increase in gene expression, and the replacement of $\mathrm{C}$ by $\mathrm{T}$ at residue 476 produced a somewhat smaller (40- to 100-fold) effect. Small but significant differences were 
Table 3. Effect of lysC leader mutations on gene expression in lys $C^{\prime}-l a c^{\prime} Z$ fusions

\begin{tabular}{lllc}
\hline \multicolumn{1}{c}{ Strain } & \multicolumn{1}{c}{ Mutation } & Type of fusion & $\begin{array}{c}\beta \text {-Galactosidase activity* } \\
\left(A_{\mathbf{4 2 0}} \mathrm{min}^{-1} \mathrm{mg}^{-1}\right)\end{array}$ \\
\hline GSY225-40 & None (wild-type) & Translational & $0 \cdot 8$ \\
GSY225-41 & $\mathrm{G}^{320} \rightarrow \mathrm{A}^{320}$ & Translational & 118 \\
GSY225-42 & $\mathrm{C}^{476} \rightarrow \mathrm{T}^{476}$ & Translational & 31 \\
GSY225-47 & $\mathrm{G}^{320} \rightarrow \mathrm{A}^{320} ; \Delta \mathrm{A}^{270}$ & Translational & $0 \cdot 0$ \\
GSY225-60 & None $($ wild-type $)$ & Transcriptional & $0 \cdot 6$ \\
GSY225-61 & $\mathrm{G}^{320} \rightarrow \mathrm{A}^{320}$ & Transcriptional & 154 \\
GSY225-62 & $\mathrm{G}^{476} \rightarrow \mathrm{A}^{476}$ & Transcriptional & 60 \\
\hline \hline
\end{tabular}

* $\beta$-Galactosidase was measured in toluene-treated cells harvested in the mid-exponential phase of growth in LB medium as described in Methods.

Table 4. Effect of L-lysine on gene expression in lys $C^{\prime}-$ lac $^{\prime} Z$ fusions

\begin{tabular}{|c|c|c|c|c|}
\hline \multirow[b]{2}{*}{ Strain } & \multirow[b]{2}{*}{ Mutation } & \multirow[b]{2}{*}{ Type of fusion } & \multicolumn{2}{|c|}{$\begin{array}{c}\beta \text {-Galactosidase activity } \\
\left(\Delta A_{420} \mathrm{~min}^{-1} \mathrm{mg}^{-1}\right) \text { in cells grown with }\end{array}$} \\
\hline & & & Excess L-lysine* & Limiting L-lysine ${ }^{*} \dagger$ \\
\hline $1 \mathrm{~A} 8-40$ & None (wild-type) & Translational & $0 \cdot 12$ & $14(117)$ \\
\hline $1 \mathrm{~A} 8-41$ & $\mathrm{G}^{320} \rightarrow \mathrm{A}^{320}$ & Translational & 53 & $44(0.83)$ \\
\hline $1 \mathrm{~A} 8-60$ & None (wild-type) & Transcriptional & $0 \cdot 15$ & $23(153)$ \\
\hline $1 A 8-61$ & $\mathrm{G}^{320} \rightarrow \mathrm{A}^{320}$ & Transcriptional & 142 & $127(0.89)$ \\
\hline
\end{tabular}

* $\beta$-Galactosidase was measured in toluene-treated cells harvested after growth in minimal medium supplemented with either limiting levels $(0.016 \mathrm{mM})$ or an excess $(5 \mathrm{mM})$ of $\mathrm{L}$-lysine as described in Methods.

$\dagger$ Numbers in parentheses: degree of derepression due to lysine limitation.

also seen in the $\beta$-galactosidase levels of translational and transcriptional fusions, but these may in part be a reflection of the relative efficiencies of the lys $C$ and the spoVG ribosome binding sites, which direct $\beta$-galactosidase synthesis in the translational and transcriptional fusions, respectively. These observations provide strong evidence that the nucleotide replacements observed on sequencing the $l y s C$ leader region of aec $A$ strains are indeed responsible for the derepression of aspartokinase II observed in aec $A$ mutants.

The effect of $\mathrm{L}$-lysine on the expression of $l y s C^{\prime}-l a c^{\prime} Z$ fusions was studied in lysine auxotrophs cultured in minimal medium with L-lysine present either at growthlimiting concentrations or in excess. Whereas the presence of an excess of L-lysine repressed $\beta$-galactosidase synthesis more than 100 -fold in both translational and transcriptional fusion strains carrying the wild-type lysC leader region, no repression by lysine was seen in strains with a nucleotide substitution at residue 320 corresponding to aecA3 (Table 4). Similarly, no repression by L-lysine was seen in strains with a nucleotide substitution at residue 476 corresponding to aec $A 4$ (data not shown). It is interesting, however, that the levels of $\beta$-galactosidase in $l y s C^{\prime}-l a c^{\prime} Z$ fusions expressed in the strains with an altered lys $C$ leader region are three to five times higher than those observed in fusion strains with a wild-type lys $C$ leader under conditions of lysine starvation (Table 4). This observation implies either that the degree of lysine starvation achieved in our experiments was not sufficient for complete derepression or that other signals, besides the availability of lysine, may be involved in the control of the lys $C$ operon.

The data presented in Tables 3 and 4 also allow certain conclusions concerning the general mechanism by which the aec $A$ mutation brings about derepression of $l y s C$. The observation that the degree of repression by L-lysine is the same in translational and transcriptional $l y s C^{\prime}-l a c^{\prime} Z$ fusions (Table 4) shows that it does not involve control of lys $C$ translation but rather the modulation of levels of functional transcripts. Does the increased transcription in the aec $A$ mutants involve the same promoter as normal lys $C$ transcription or is it due to the activation of a new promoter? Earlier studies on transcript mapping and promoter analysis of the lys $C$ operon showed that normal transcription initiation occurs near residue 280 and that the promoter straddles the $B g l \mathrm{II}$ site at residue 262 , which is flanked by the -35 and -10 consensus sequences associated with promoters recognized by the major B. subtilis RNA polymerase (Chen et al., 1987). Our observation that strain GSY225-47, which differs 
from the derepressed mutant GSY225-41 by the deletion of a single residue (270) in the -10 consensus element, completely lacked the ability to express the $l y s C^{\prime}-l a c^{\prime} Z$ fusion protein (Table 3 ) demonstrates that both wildtype and mutant lys $C$ expression involve the same promoter.

\section{Conclusions}

The results presented here show that aecA mutations involve the replacement of one or two nucleotide residues in the lys $C$ leader region. The mutations studied define two distinct sites in the lysC leader, the alteration of which causes approximately 100 -fold increases in the levels of functional lysC mRNA and which must, therefore, play an important role in the control of aspartokinase II levels. Whether these control sites, located near residues 320 and 476 , act independently or together, and how they relate to other control elements, such as the putative transcription attenuator (Chen et al., 1987), are important questions that remain to be addressed.

Although this work has identified the aecA loci as important control sites in the lys $C$ operon, very little can be said at this time about the molecular mechanisms by which these loci participate in the control of transcription. Examination of the nucleotide sequence of the lys leader region (Fig. 3) fails to reveal clear-cut relationships between the nucleotides surrounding residues 320 and 476 and other potential control elements, such as the promoter and the putative transcription attenuator. Except for a region of imperfect dyad symmetry centred on residue 320 , no indications of potential secondary structure or possible base-pairing interactions with other sites in the lys $C$ leader region, at the level of either DNA or RNA, can be discerned. Indeed, it is hard to see how a substitution of $\mathrm{A}$ for $\mathrm{G}$, or of $\mathrm{T}$ for $\mathrm{C}$, the basis of the two aec $A$ mutations studied, could produce major alterations in nucleic acid secondary structure, and the possibility that the sites defined by the aec $A$ mutations may be the targets of as yet unidentified trans-acting control elements merits serious consideration. The 330 nucleotide length of the lys $C$ leader region is exceptionally large for prokaryotic operons, suggesting that it may be the site of unusual or novel control mechanisms. Interestingly, the lysC leader region of $E$. coli, at 308 nucleotide residues, is almost as extensive as that of $B$. subtilis but differs from the latter by the absence of elements resembling a transcription attenuator (Cassan et al., 1983). Further analysis of the control sites in the lysC operon of $B$. subtilis defined by the aecA mutations should provide interesting insights into the regulation of this complex operon.
We thank Drs Lars Hederstedt, Issar Smith and Dennis Henner for generously providing $B$. subtilis KA120, plasmid pIS112 and plasmid pDH32, respectively. This research was supported by Grant DMB 8803644 from the National Science Foundation and by Biomedical Research Support Grant RR 05711 from the National Institutes of Health Research Support Program.

\section{References}

Anagnostopoulos, C. \& Spizizen, J. (1961). Requirements for transformation in Bacillus subtilis. Journal of Bacteriology 81, 741-746.

BRADFORD, M. M. (1976). A rapid and sensitive method for the quantitation of microgram quantities of protein utilizing the principle of protein-dye binding. Analytical Biochemistry 72, 248-254.

Cassan, M., Ronceray, J. \& Patte, J. C. (1983). Nucleotide region of the promoter region of the E. coli lysC gene. Nucleic Acids Research 11, 6157-6166.

Chen, N. Y., Hu, F. M. \& Paulus, H. (1987). Nucleotide sequence of the overlapping genes for the subunits of Bacillus subtilis aspartokinase II and their control regions. Journal of Biological Chemistry 262, 8787-8798.

Chen, N. Y. \& Paulus, H. (1988). Mechanism of expression of the overlapping genes of Bacillus subtilis aspartokinase II. Journal of Biological Chemistry 263, 9526-9532.

Chen, N. Y., Zhang, J. J. \& Paulus, H. (1989). Chromosomal location of the Bacillus subtilis aspartokinase II gene and nucleotide sequence of the adjacent genes homologous to uvrC and trx of Escherichia coli. Journal of General Microbiology 135, 2931-2940.

Dedonder, R. A., Lepesant, J. A., Lepesant-Kejzlarova, J., Billault, A., Steinmetz, M. \& Kunst, F. (1977). Construction of a kit of reference strains for rapid genetic mapping in Bacillus subtilis 168. Applied and Environmental Microbiology 33, 989-993.

Ferrari, F. A., Nguyen, A., Lang, D. \& Hoch, J. A. (1983). Construction and properties of an integratable plasmid for Bacillus subtilis. Journal of Bacteriology 154, 1513-1515.

KUNKEL, T. A. (1985). Rapid and efficient site-specific mutagenesis without phenotypic selection. Proceedings of the National Academy of Sciences of the United States of America 82, 488-492.

LEWANDOSKI, M. \& SMITH, I. (1988). Use of a versatile $l a c Z$ vector to analyze the upstream region of the Bacillus subtilis spoOF gene. Plasmid 20, 148-154.

Magnusson, K., Rutberg, B., Hederstedt, L. \& Rutberg, L. (1983). Characterization of a pleiotropic succinate dehydrogenase-negative mutant of Bacillus subtilis. Journal of General Microbiology 129, 917-922.

Mattioli, R., Bazzicalupo, M., Federici, G., Gallori, E. \& Polsinelli, M. (1979). Characterization of mutants of Bacillus subtilis resistant to $S$-(2-aminoethyl)cysteine. Journal of General Microbiology 114, 223-225.

Miller, J. H. Experiments in Molecular Genetics, Cold Spring Harbor, NY : Cold Spring Harbor Laboratory.

MoIR, D. \& Paulus, H. (1977). Properties and subunit structure of aspartokinase II from Bacillus subtilis VB217. Journal of Biological Chemistry 252, 4648-4654.

Nakamaye, K. \& ECKstein, F. (1986). Inhibition of restriction endonuclease $\mathrm{Nci}$ cleavage by phosphorothioate groups and its application to oligonucleotide-directed mutagenesis. Nucleic Acids Research 14, 9679-9698.

Paulus, H. \& Gray, E. (1967). Multivalent feedback inhibition of aspartokinase in Bacillus polymyxa: I. Kinetic studies. Journal of Biological Chemistry 242, 4980-4986.

PetriceK, M., Rutberg, L. \& Hederstedt, L. (1989). The structural gene for aspartokinase II in Bacillus subtilis is closely linked to the $s d h$ operon. FEMS Microbiology Letters 61, 85-88.

Piggot, P. J. \& Hoch, J. A. (1985). Revised genetic linkage map of Bacillus subtilis. Microbiological Reviews 49, 158-179. 
SANGer, F., Nicklen, S. \& Coulson, A. R. (1977). DNA sequencing with chain-terminating inhibitors. Proceedings of the National Academy of Sciences of the United States of America 74, 54635467.

Shimotsu, H. \& Henner, D. J. (1986). Construction of a single-copy intergration vector and its use in analysis of regulation of the trp operon of Bacillus subtilis. Gene 43, 85-94.

Stansly, P. G., Shepherd, R. G. \& White, H. J. (1947). Polymyxin: new chemotherapeutic agent. Bulletin of the Johns Hopkins Hospital 81, 43-54.

TABOR, S. \& RICHARDSON, C. C. (1987). DNA sequence analysis with a modified bacteriophage T7 DNA polymerase. Proceedings of the
National Academy of Sciences of the United States of America 84, 4767-4771.

Vold, B., Szulmajster, J. \& Carbone, A. (1975). Regulation of dihydrodipicolinate synthase and aspartate kinase in Bacillus subtilis, Journal of Bacteriology 121, 970-974.

YeH, E. C. \& SteinberG, W. (1978). The effect of gene position, gene dosage and a regulatory mutation on the temporal sequence of enzyme synthesis accompanying outgrowth of Bacillus subtilis spores. Molecular and General Genetics 158, 287-296.

Zhang, J. J., Hu, F. M., Chen, N. Y. \& Paulus, H. (1990). Comparison of the three aspartokinase isozymes in Bacillus subtilis Marburg and 168. Journal of Bacteriology 172, 701-708. 